International Journal of Engineering \& Technology, $7(2.33)(2018) 473-476$
International Journal of Engineering \& Technology
SPC
Website: www.sciencepubco.com/index.php/IJET
Research paper

\title{
Design \& development of vehicular micro strip patch antenna for emergency vehicle
}

\author{
Ebenezer Abishek. B ${ }^{1 *}$, Dr. Arun Raaza ${ }^{2}$, Dr. V. Rajendran ${ }^{3}$ \\ ${ }^{1}$ Research Scholar, Vels University \\ ${ }^{2}$ Deputy Director, CARD, Vels University \\ ${ }^{3}$ HoD and Professor-ECE Dept, Vels University \\ *Corresponding author E-mail: abishek.se@velsuniv.ac.in
}

\begin{abstract}
Life threat events can occur during Traffic congested peak hours. Emergency vehicles are mostly stuck in the traffic jams because people are unaware of traffic rules, no separate lanes for emergency vehicles. Traffic jams in case of health emergencies and emergencies like fire accident lead to increase in death rate. The loss of precious life can be avoided by efficient traffic management system. In this paper a microstrip antenna is designed and developed with radiation characteristics best suited for the emergency vehicles. Emergency vehicle alert for short-range vehicular networks will be implemented using the fabricated antenna.
\end{abstract}

Keywords: Emergency Vehicle; Micro Strip Patch Antenna; RT Duroid; Traffic Jams; Traffic Light. .

\section{Introduction}

A novel idea of detecting and notifying the arrival of Emergency vehicles like Ambulance, Fire Engine or Police Patrol even before its line of sight to the other moving vehicles to the nearest traffic light using micro strip antenna is proposed. A prototype for emergency vehicle alert for short range vehicular networks using the fabricated antenna is also developed. The omnidirectional gain advantages of micro strip antenna in Emergency Vehicle Alert is utilized. The micro strip has compact shape, size, low cost with good radiation characteristics.

\section{Design \& development of antenna for emer- gency vehicles}

The micro strip patch antenna's dimensions were determined using the patch antenna design equations. The determined dimensions are shown in table below.

Table 1: Dimensions of Micro Strip Patch Antenna for Emergency Vehicles.

\begin{tabular}{ll}
\hline PARAMETERS & Dimensions in mm \\
\hline Width of the Patch (W) & 15.472 \\
Actual Length of the Patch (L) & 11.537 \\
Thickness of the Substrate & 1.6 \\
\hline
\end{tabular}

The designed micro strip antenna resonating at $5.9 \mathrm{GHz}$ suitable for vehicular communication in CADFEKO toolis shown in figure below

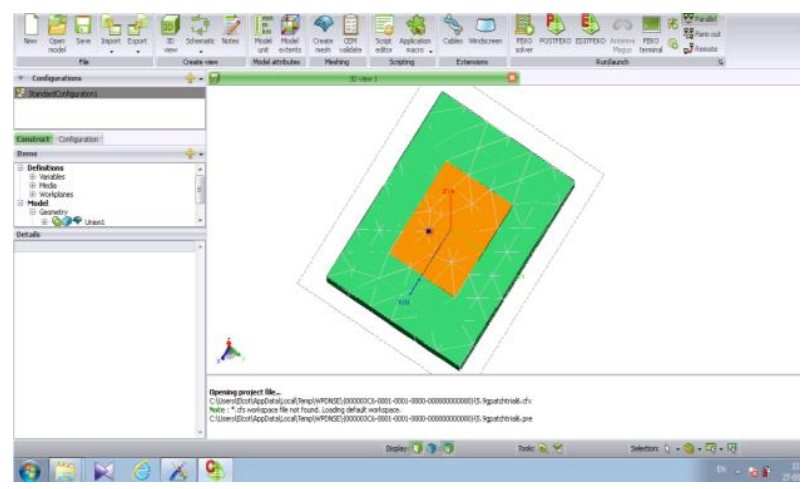

Fig. 1: Designed Microstrip Patch Antenna for Emergency Vehicles.

\section{Simulation results}

The [3] dimensional far field pattern of the designed microstrip patch antenna simulated in POSTFEKO tool is shown in figure below

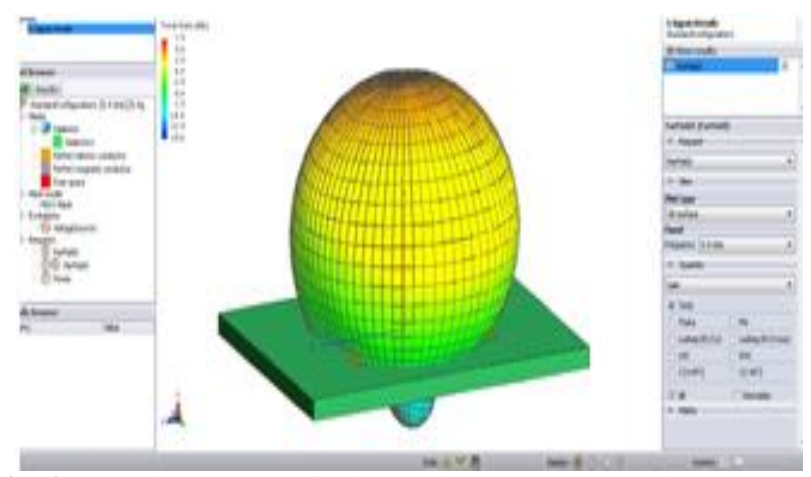

Fig. 2: Far Field Pattern of Micro Strip Patch Antenna for Emergency Vehicles. 
The reflection coefficient of the designed microstrip patch antenna simulated in POSTFEKO tool is shown in figure below.

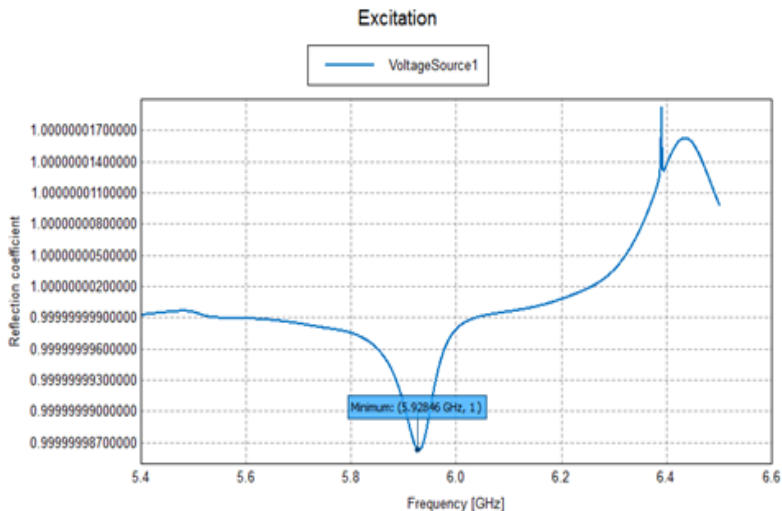

Fig. 3: Reflection Coefficient of Micro Strip Patch Antenna for Emergency Vehicles.

\section{Fabrication and testing of antenna for emergency vehicles}

After getting the required output through simulation software, the design was fabricated. Material used as a substrate is FR4-epoxy whose Dielectric constant is 4.4 and the substrate height is $1.6 \mathrm{~mm}$. The feed point is drilled and the connector is soldered at that spot. The connector used out here is 50ohm SMA N-type female connector. The proposed designed antenna fabricated using FR4 dielectric material and is shown below.

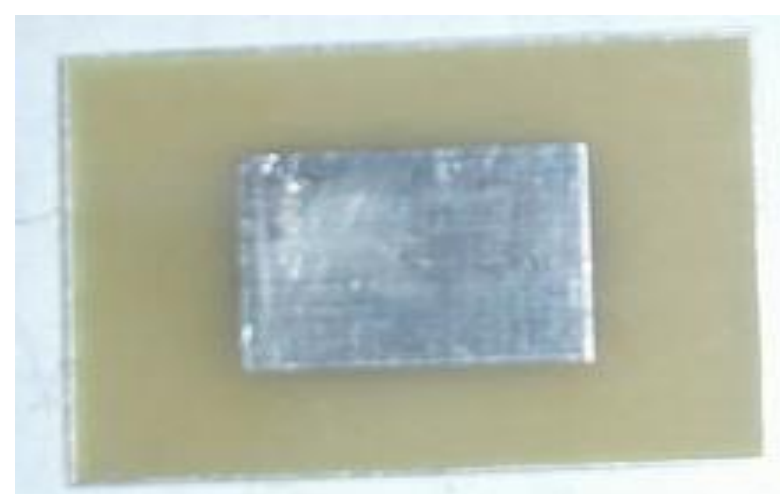

Fig. 4: Fabricated Micro Strip Patch Antenna for Emergency Vehicles.

The testing the fabricated antenna was done using Vector network analyzer and the various results are shown in figures below

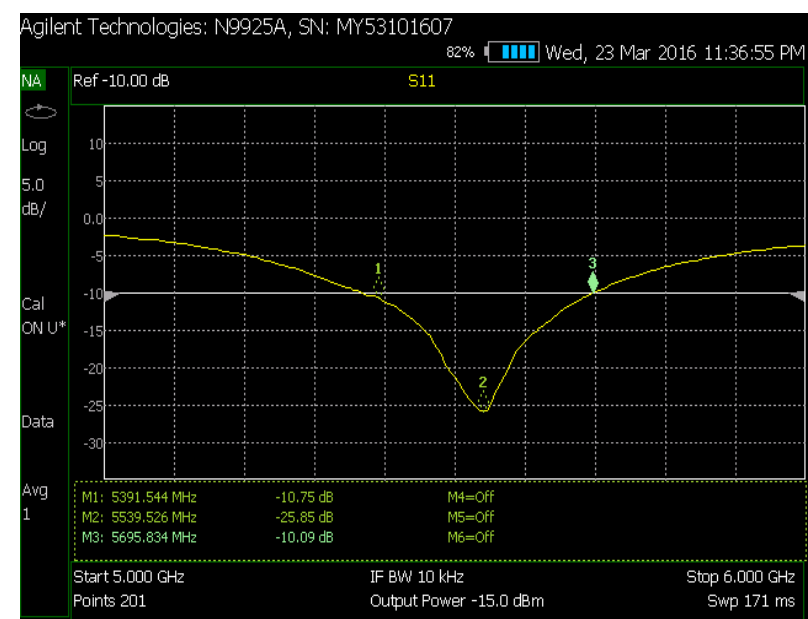

Fig. 5: Measured S11 Parameter.

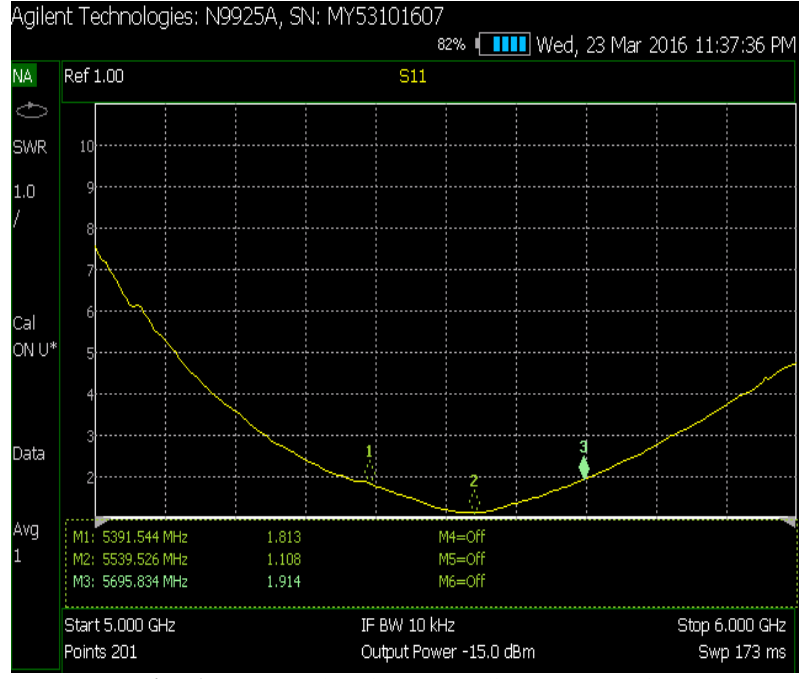

Fig. 6: Measured Voltage Standing Wave Ratio.

The measured results shows good agreement with the simulated results and thus the simulation results are validated.

\section{Proposed prototype}

The transmitting antenna is placed in the top of the emergency vehicle whereas the receiver is placed in the other moving vehicle as well as traffic signal controller. The transmitter is operated manually which sends the emergency alert indication to the receiver in the form of electromagnetic waves. The receiver in the traffic signal controller controls the traffic light in such a way that till the emergency vehicle crosses the traffic signal, red signal will not occur. Whereas the receiver in other vehicles will receive an alert message that to leave way for the emergency vehicle to pass through. Thus using this effective traffic management system, the emergency vehicles transport will be able to save time and in turn save precious lives. This prototype is illustrated in figure below.

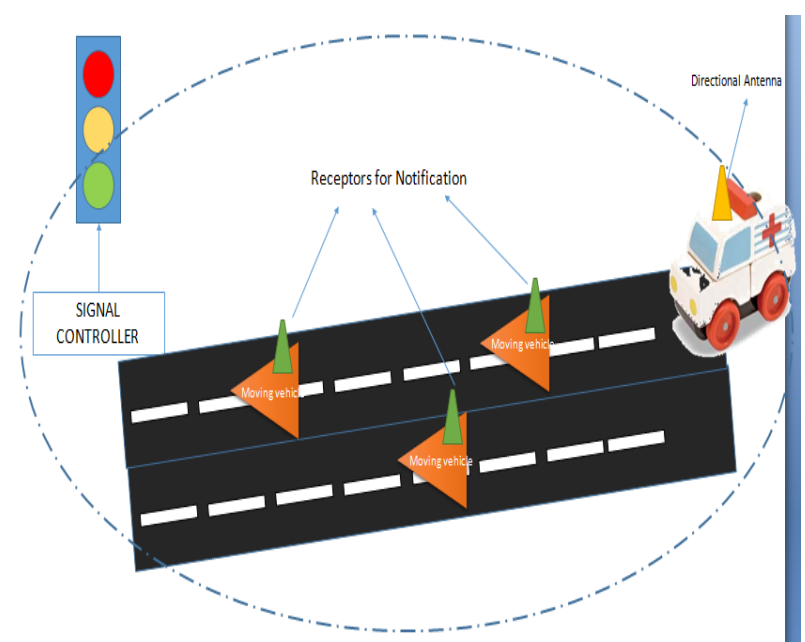

Fig. 7: Prototype utilizing the Patch Antenna for Emergency Vehicles.

This traffic light controller system consists of data receptor antenna, microcontroller and traffic light. The data receptor antenna receives the signal send the information to the controller. After the controller receives the information it controls the time of the light in the timer. this process can be achieved by using high gain antennas because antenna gain play a major role for transmitting and receiving purposes. 


\section{Fabrication and testing of antenna for emergency vehicles}

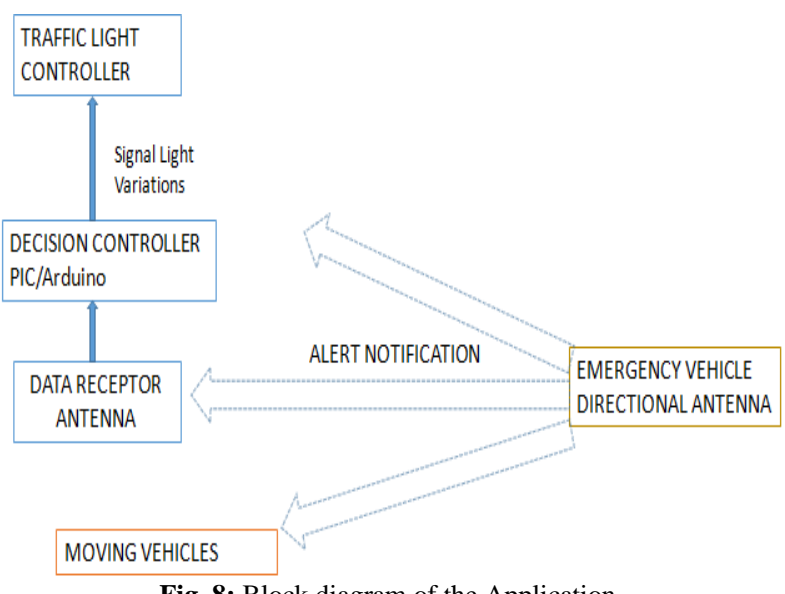

Fig. 8: Block diagram of the Application.

The above figure illustrates how the traffic signal is being functioned by the trigger of Microstrip antenna's radiation pattern. As soon as the radiation pattern of transmitting antenna placed at the top of EM vehicle coincides with the radiation pattern of receiving antenna placed at the traffic signal, it triggers the microcontroller connected to it. By getting triggered the microcontroller performs the task given to it.

\section{Traffic light control}

Generally in a four way junction the control of traffic light and sudden change of signal is difficult. So, by connecting the single microcontroller to all the signals the control of traffic signal becomes easier. The traffic light control is illustrated in figure below.

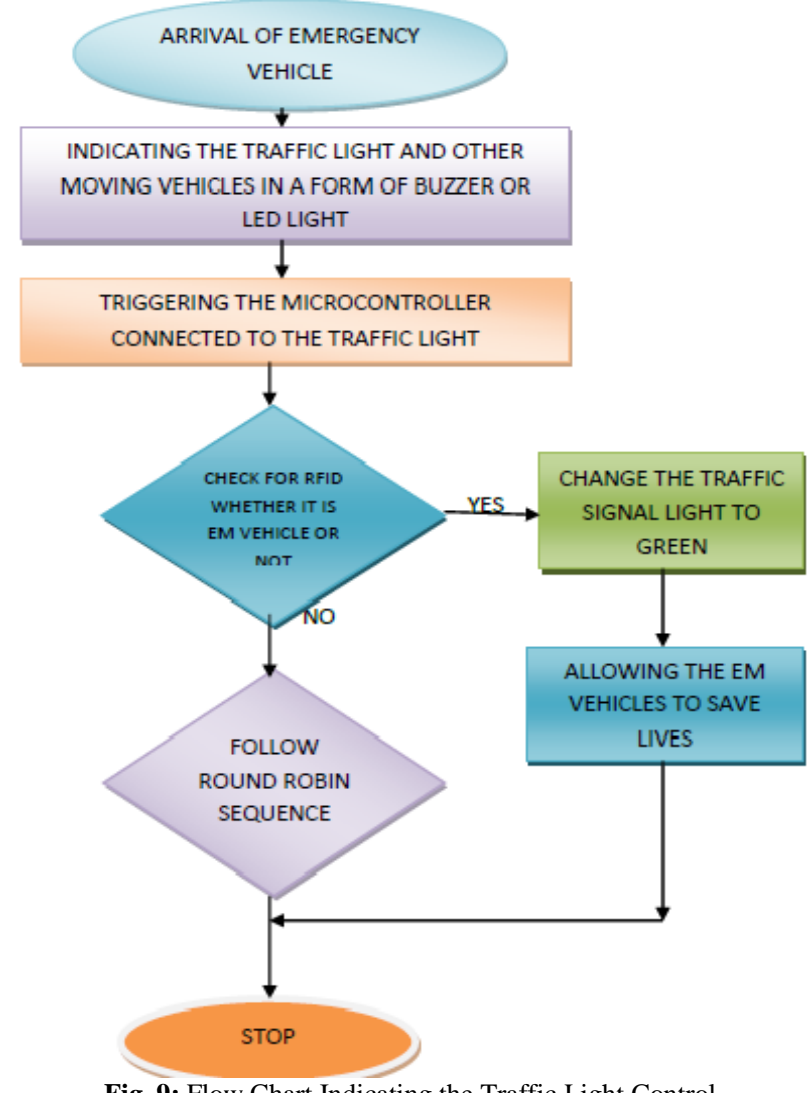

Fig. 9: Flow Chart Indicating the Traffic Light Control.
The Traffic light follows the conventional Round Robin Technique before the transmitting antenna radiation from emergency vehicle reaches the radiation pattern of receiving antenna placed at traffic signal as illustrated in figure below.

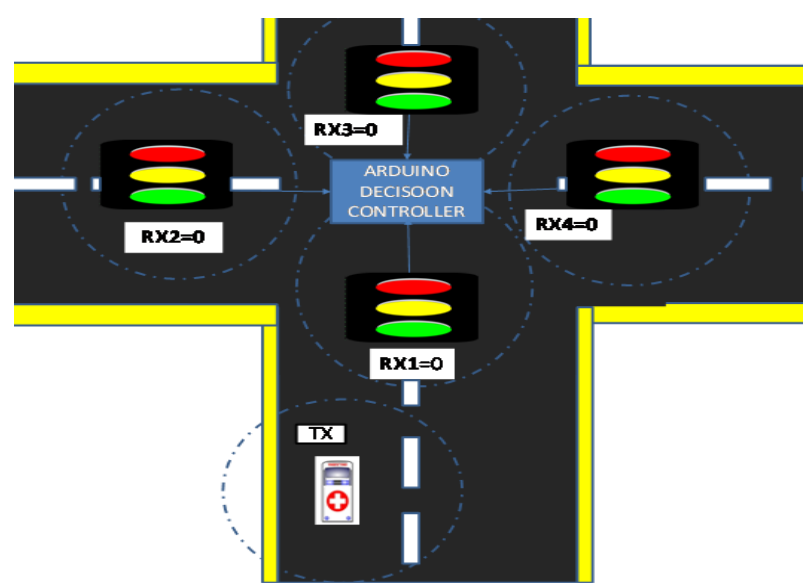

Fig. 10: Traffic Light Working in Round Robin Approach.

As soon as the Transmitting antennas radiation pattern reaches the radiation range of nearby receiving antenna, the Round robin technique gets lower priority and the Arduino board performs the task given to it as illustrated in figure below.

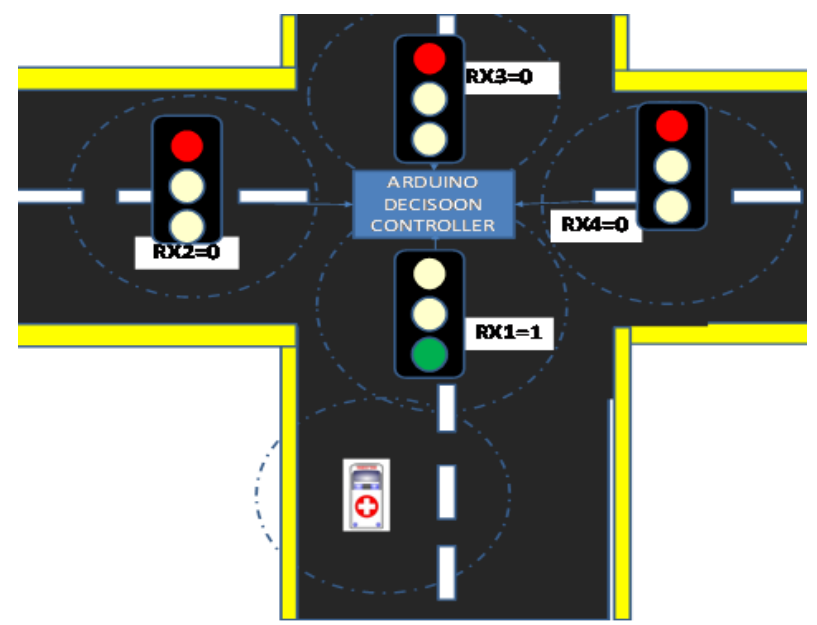

Fig. 11: Traffic Light is controlled by the System Utilizing the Developed Vehicular Antenna.

After the Emergency vehicles radiation pattern moves away from the signals coverage area, again the conventional round robin technique is followed as shown in figure below.

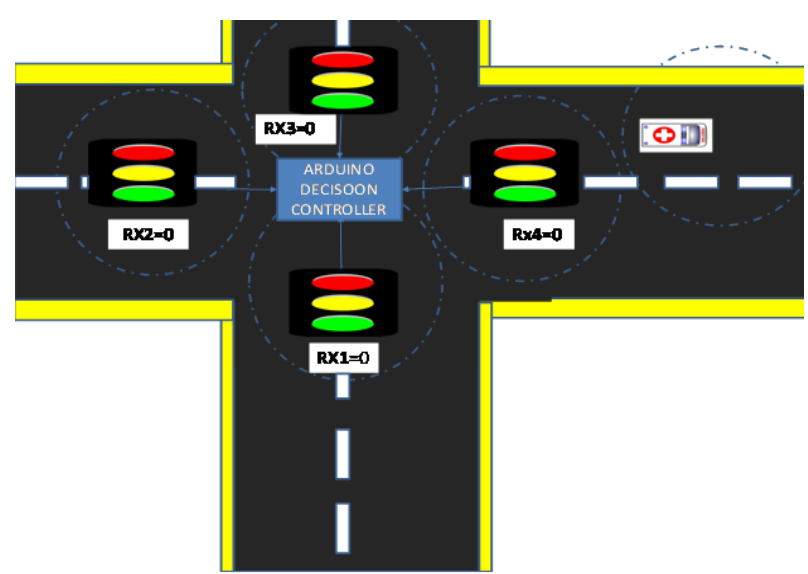

Fig. 12: After the Emergency Vehicle Passes Away, the Traffic Light Again Works in Round Robin Approach. 


\section{Conclusion}

By using high gain antennas due to its high gain nature the information will reach its destination correctly even there is a presence of interferences. This method we can give a lane for emergency vehicles to reach its destination as much as possible and also can control the life threat during traffic congested peak hours.

\section{References}

[1] E. B. Abishek, A. V. P. Raja, K. P. C. Kumar, A. C. Stephen, and A. Raaza, "Study and analysis of conformal antennas for vehicular communication applications," ARPN J. Eng. Appl. Sci., vol. 12, no. 8, pp. 2428-2433, 2017

[2] E. A. B et al., "International Journal of Control Theory and Applications Modal Analysis and Harmonic Analysis of a Conformal Antenna for Automobile Applications," vol. 10, pp. 17-23, 2017.

[3] Ebenezer Anishek.B,Meena, M., \&S.Jerritta. (2015). FPGA IMPLEMENTATION OF RELIABLE NOC, 10(17), 31835-31843.

[4] Almalkawi, M. J. (2015). High Gain Circularly Polarized Wire Antenna for DSRC Applications, 9(6), 592-595.

[5] Hashim, N. M. Z., Jaafar, A. S., Ali, N. A., Salahuddin, L., Mohamad, N. R., \& Ibrahim, M. A. (2013). Traffic Light Control System for Emergency Vehicles Using Radio Frequency, 3(7), 43-52.

[6] Ir, A., Khairuddin, W. A. N., \& Ali, W. A. N. (2004). Wideband Microstrip Antenna for Land Based Vehicles (Antenna Jalurmikro Berjalur Frekuensi Lebar Untuk Kegunaan Kenderaan Darat), (October).

[7] Journal, I., Science, E., \& Technology, I. (2014). Design of an Intelligent Auto Traffic Signal Controller with Emergency Override, 3(4), 670-675.

[8] Koch, N. (n.d.). Antennas for Automobiles

[9] Akande S. F. (2003) VHF/UHF Communications. A Postgraduate Course in the Department of Physics, University of Jos. Unpublished.

[10] Burkholder, R and Lundin, T. (2006). Antenna and Radiation Pattern. IEEE. Transactions on Antennas and Propagation, 53(2)

[11] Gonca, C. (2005) Design, Simulation and Tests of Low-cost Microstrip Patch Antenna Arrays for the Wireless Communication Turk J Elect Engin

[12] Richards, W.F. (1988) Microstrip Antennas. Theory, Application and Design. Van Reinhold Co., New York

[13] A. Ferrara and J. Paderno, "Application of switching control for automatic pre-crash collision avoidance in cars," Nonlinear Dyn., vol. 46, no. 3, pp. 307-321, Nov. 2006.

[14] Constantine A. Balanis, "ANTENNA THEORY ANALYSIS AND DESIGN," Circular patch., pp. 843-852.

[15] Huang, "Circularly Polarized Conical Patterns from Circular Microstrip Antennas," IEEE Trans. Antennas Propagation. 